\title{
Article \\ The Holy Light of Cyberspace: Spiritual Experience in a Virtual Church
}

\author{
Nesrine Mansour
}

Citation: Mansour, Nesrine. 2022.

The Holy Light of Cyberspace:

Spiritual Experience in a Virtual

Church. Religions 13: 121. https:// doi.org/10.3390/rel13020121

Academic Editor: Tammy Gaber

Received: 2 December 2021

Accepted: 18 January 2022

Published: 26 January 2022

Publisher's Note: MDPI stays neutral with regard to jurisdictional claims in published maps and institutional affiliations.

Copyright: (C) 2022 by the author. Licensee MDPI, Basel, Switzerland. This article is an open access article distributed under the terms and conditions of the Creative Commons Attribution (CC BY) license (https:// creativecommons.org/licenses/by/ $4.0 /)$.
School of Design, South Dakota State University, Brookings, SD 57007, USA; nesrine.mansour@sdstate.edu

\begin{abstract}
Digital technology became a substantial component of daily life activities where people grew less dependent on the constraints of the physical world. Recent developments of new media platforms have led to important changes in religious practices, resulting in digital religion. However, there is a lack of empirical research assessing the effect on the spiritual experience. Some elements of sacred architecture, light for instance, influence the perception and experience of space. Light is a symbol of the sacred as it uplifts the worshiper's soul and contributes to the transcendental experience. This paper proposes an analysis of a contemporary space, cyberspace, in framing the sacred experience. The focus is on light and its effect on the spiritual experience in a virtual church. The method employs an empirical approach, adapted from the social sciences scholarship, to examine the extent of the spiritual experience(s) manifested by the participants as emotional responses to the sacred space. The findings highlight people's experiences of the cyber-sacred space and offer insights into the design of those spaces. This spiritual event could be considered a spiritual appreciation of architectural elements translated as subjective emotional responses to virtual sacred architecture. Such study bridges the research of architecture and social sciences in creating a platform for the empirical exploration of virtual 'built' environments. It provides a quantitative approach to a phenomenological concept of digital religion and the future of spiritual practices related to virtual sacred architecture. The importance of the study lies on the designed methodology to assess the effect of light on the spiritual experience in virtual sacred architecture.
\end{abstract}

Keywords: sacred architecture; light; spiritual experience; digital religion

\section{Introduction}

New technologies and the incorporation of digital media into our daily lives have transformed our perception of reality, creating a blurred line between real and virtual realms. Virtual environments became free of physical constraints, which facilitates building new parallel worlds driven by an unlimited imagination. With the emergence of the Internet in the 1990s, cyberspace originated to become an extension of our physical and temporal existence (Kalay and Marx 2005; Rain and Lorents 2010; Ning et al. 2018). Digital technologies have transformed our society, resulting in the advent of new trends in education, business, and religious practices, among others. Today, cyberspace is a place where we perform daily tasks such as shopping (e.g., Amazon), working and conducting virtual meetings (e.g., Zoom space), learning, entertainment, and attending religious gatherings, to name a few applications (Abu-Taieh et al. 2020). The Internet and cyberspace triggered myriad studies, one of them being the development of a new phenomenon named digital religion (Campbell 2012; Wagner 2013; Campbell and Tsuria 2021).

Digital religion is a neologism developed in the last few decades showing how digital media and spaces are shaping and being shaped by religious practices (Campbell 2012; Campbell and Tsuria 2021). This concept reflects the inter-relationship between religion, media, and culture. Some examples of such interaction manifest as cyber, online or e-churches, religious radios and blogs, online prayers, online or e-bible study, virtual pilgrimages, televangelism (i.e., religious TV broadcasts), etc. Literature emerging from the study 
of digital religion focuses largely on the written narrative (Hoover and Echchaibi 2012; Helland 2016), and not necessarily on the graphical and visual expressions of religious spaces, despite the suggestive evidence that virtual representations of religious buildings may facilitate a spiritual experience similar to the ones in real houses of worship (Gelfgren and Hutchings 2014). The E-Church ${ }^{1}$ concept was one of the first manifestations of digital religious practices which relied mainly on religious textual discourse rather than graphical representation of the sacred cyberspace (Schroeder et al. 1998; Campbell 2005; Hutchings 2011). Thus, research on the visual representation of sacred architecture in the digital religion phenomenon is lacking. However, the architecture of religious and spiritual spaces is recognized to possess a theological and spiritual character that contributes to the spiritual experience (Carroll 2003).

A substantial amount of research deals with the representation of culture and heritage, especially the sacred ones that use digitization techniques (MacDonald 2006; Thwaites 2013). Indeed, digital heritage portrays the intersection of cultural heritage and digital media (Parry 2007). Though scholars believe in the importance of the visual representation of digital sacred architecture in digital religion (Gelfgren and Hutchings 2014; Campbell 1995), research is still lacking from the design fields. This paper attempts to fill this gap by proposing an empirical method to assess the extent of the spiritual experience conveyed as emotional responses to virtual sacred architecture. Specifically, the focus is on how to assess the effect of light, a major element of sacred architecture, on the spiritual experience in a virtual sacred space.

\section{Light and Sacred Architecture: Real and Virtual}

\subsection{Sacred Architecture}

Before addressing light as an important element of sacred architecture, one ought to commence with an ontological approach to the definition of what is sacred architecture. According to liturgical writings, especially Christian writings from distinct denominations, a sacred place is a place consecrated for divine worship (Woywod 1918). Architecture has served as a shelter and a provider of comfort and beauty for human beings, but sacred architecture moves beyond the physical needs to impart spiritual needs as well. Humans attempt to reflect a divine presence through the use of architectural features and dimensions that create the space (Jones 2000). Famous examples of sacred architecture range from Gothic cathedrals such as Notre Dame in Paris, monolithic structures in the form of Stonehenge and the Pyramidal formations in Mayan and Egyptian civilizations, to a simple cube depiction of divine presence such as Mecca. These sites, whether seen through images, videos, or in reality, clearly exude a sense of sacredness heavily related to religious beliefs. Jones claims that in order to understand sacred architecture, we ought to understand the religion (i.e., the faith) (Jones 2000). In fact, sacred architecture is a representation of the religious experience of humankind, individuals or communities (Jones 2000). Sacred architecture possesses a "quality of allurement" people are drawn to, to revive their identity. Such spaces are made of tangible and intangible material substances, one of them being the quality of light. The mythical and poetic quality of a space is mainly created by the variation of shadow and light (Birch and Sinclair 2013), thus this inquiry revolves around the significance of light in sacred architecture.

\subsection{Light and Sacred Architecture}

The importance of light in architecture has been extensively discussed in a plethora of architectural literature produced by scholars and architects. Le Corbusier affirmed that light highlights architecture as "architecture is the masterly, correct, and magnificent play of masses brought together in light. Our eyes are made to see forms in light; light and shade reveal those forms" (Corbusier 1931, p. 29). Similarly, Frank Lloyd Wright and Louis Kahn believed that light beautifies architecture (Geva 2011). Light is indeed a symbol of the sacred, cosmological, and religious beliefs illustrating the connection of humans with a higher order of things, with the essential, and the perception of the immutable divine 
presence (Schwarz 1958; Plummer 1987). Light streaming onto a sacred building creates a dramatic effect enhancing the axis mundi-the axis of the world-where Heaven and Earth melt into one to bring humans closer to God (Schwarz 1958; Geva 2011). The concept of "Holy" light, associated with divine light or natural light, not only beautifies the sacred space, but also expresses a sense of purity, eternity, and a feeling of hope, hence the choice of "Holy Light" as the title for this paper. Particularly, light is considered a fundamental element in Christianity and Christian architecture (Gojnik and Gojnik 2018). It is perceived as the presence of the Divine, as at the beginning of the story of creation, God said "Let there be light, and there was light. God saw that the light was good, and he separated light from the darkness" (Genesis 1:3). The importance of light in Christianity is empathized further in the Gospel of John where Jesus said, "I am the light of the world; he who follows me will not walk in darkness but will have the light of life" (John 8:12) and "While you have the light, believe in the light, so that you may become sons of light" (John 12:36). Across religions, light exudes the manifestation of God, and everything originates from it (Matracchi and Sadeghi Habibabad 2021). The focus in this paper on light in Christian architecture stems from its importance both in the physical aspect of vision and the symbolic qualities to enhance divine presence (Figure 1).

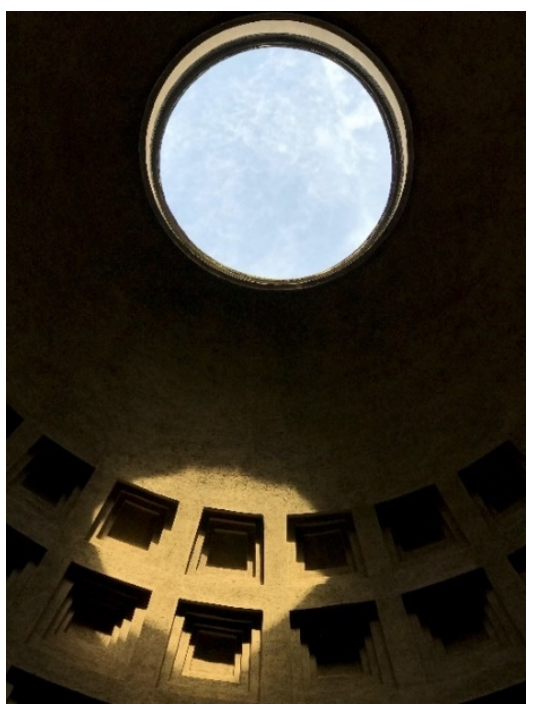

Figure 1. The Oculus in the Pantheon, Rome. Source: Author.

\subsection{Light and Virtual Sacred Architecture}

Digital media is overwhelmingly present in our lives encompassing the intersection of religion and sacred architecture by the use of digital tools. Digital religion ${ }^{2}$ is a medium creating new virtual realities that enable individuals to practice religious rituals. The newly formed virtual sacred spaces are translated through virtual models of buildings found in games, mobile applications, videos, and websites. The virtual environment that surfaced from the development of computers and the Internet, or cyberspace, became an extension of the physical reality (Gibson 1984; Kalay 2004). The new digital virtuality permits the notion of three-dimensionality, interactivity, immersion, and multimedia phenomenon (Bermudez 1999). These virtual realities offer unlimited possibilities for architectural styles and religious features. Such possibilities are expressed in the form of religious virtual buildings and sacred spaces. Since this study's interest is mainly light in Christian buildings, the definite examples of virtual sacred architecture examined are churches.

Churches' websites generally include series of images where the light sources vary depending on the context (e.g., sanctuary, chapel, praying hall, etc.). Phones and/or tablets applications showcase virtual reconstructions of churches. For example, The Sanctuary Application depicts light as a real-time three-dimensional interactive experience inside a virtual church (The Sanctuary App on the App Store 2011). The light comes from the side 
walls surrounding the space through a combination of stained and clear glass windows. Additional example would be a virtual tour of the Saint Jean Cathedral in Lyon, France (Saint Jean Cathedral in WebGL 2019), where light can be experienced through the digital representation. The developer offers the option to manipulate the light attributes (e.g., intensity, shadows, specular properties, etc.), as well as the direction of the sun outside the building.

Live broadcasts are other examples where artificial light is used to enhance the digital quality of video broadcasting (e.g., Lakewood Church in Houston, Life TV Church in Colorado, Hillsong Churches around the world). In games and virtual worlds such as Second Life, more design varieties and options are used since players sometimes become the designers of their own worlds. For instance, a Second Life user from a Christian (Catholic) background describes the quest for a spiritual experience in the virtual world as "So off I went in search of beautiful churches. I especially love stain glass windows and am enchanted by religious art. I found Walsingham Church with its simple interiors, St Paul and its large stained-glass windows, the sweet gilt display of the blessed child at St George and the wondrous Basilica Cardinale. The Basilica was stunning with stained glass, ornate alter and prayer pews for the patrons. I loved it here and we stayed [in the virtual world] for about an hour." (Rafeejewell 2009) (Figures 2 and 3).

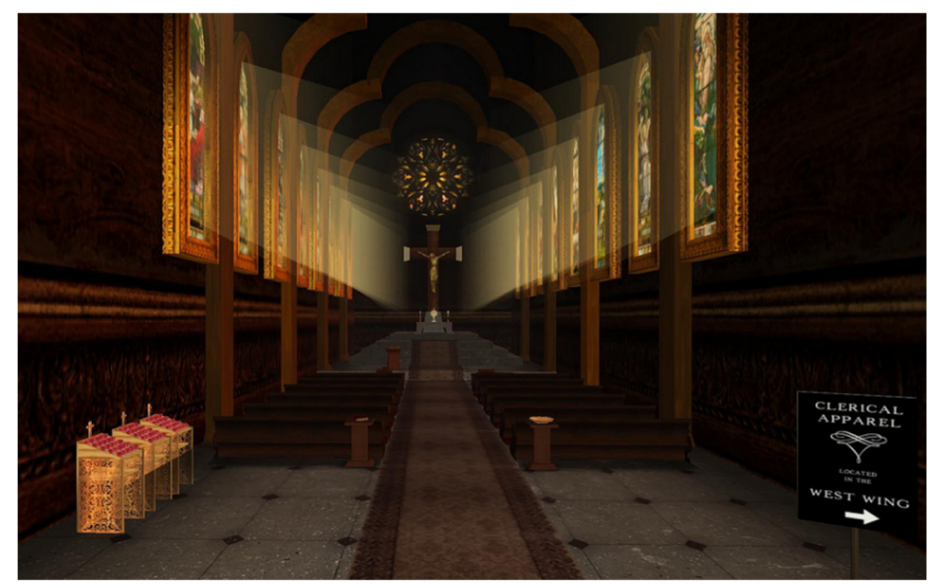

Figure 2. Basilica Cardinale Source by (Rafeejewell 2009).

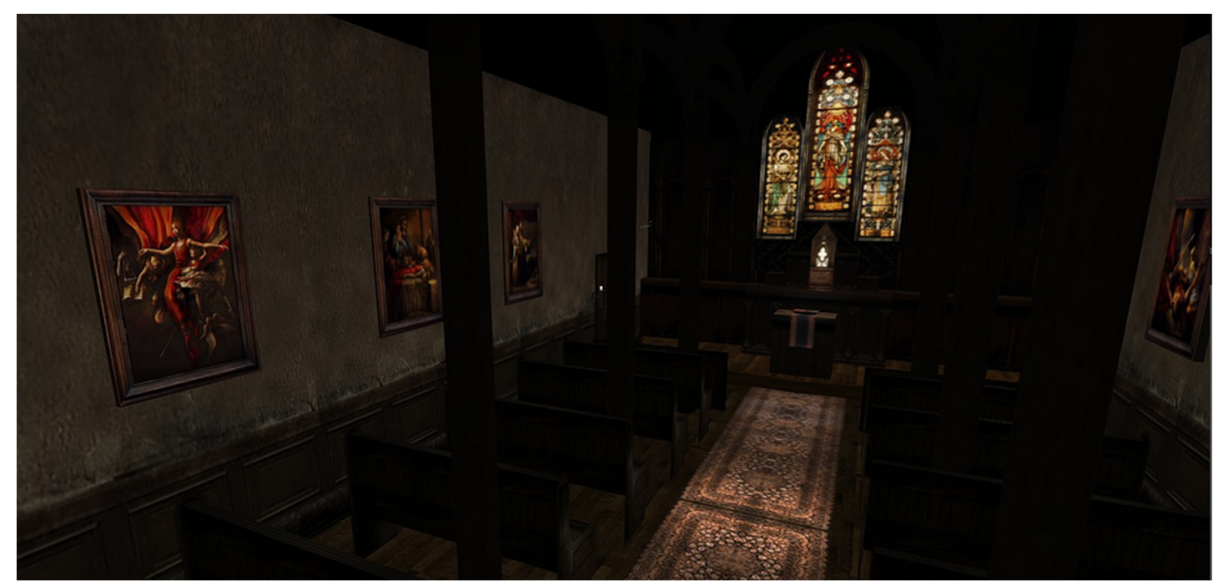

Figure 3. Example of a Virtual Church. Source by (Jamiecat 2010).

The literature and observations of examples representing light in virtual sacred spaces do not provide an empirical evaluation of the light effect on the spiritual experience in such spaces. Therefore, this study offers an innovative empirical method to assess that effect while using light in cyberspace as the main architectural element. 


\section{Spiritual Experience}

Spiritual experiences tend to move to digital spaces in the shape of virtual worlds (e.g., Second Life), forums, chatrooms, games, and social media (Campbell 2012). The fast-changing facets of religious practices and their interactions with the digital world raise questions about the design of these virtual sacred spaces. This paper uses an empirical method embedded in the digital space to investigate the question: does architectural design of virtual sacred spaces, in particular the manipulation of architectural light (intensity) in a virtual church, have an effect on the spiritual experience expressed as an emotional response by the digital worshipers?

Spirituality can be defined as the continuous human yearning for something larger than the ego (Palmer 2003); or the experience of the transcendent, regardless of the religious belief (Bento 2000); or the inner experience at the encounter of the beyond (Lewis and Geroy 2000). The common ground between religion and spirituality is posited as a search for the sacred (Zinnbauer et al. 1999). In the Hermeneutics of sacred architecture, Jones expresses the existence of an inter-relationship between the built form, ritual processes, and spiritual experiences in sacred architecture (Jones 2000). Human experience is determined by the senses and their reaction to external objects (Watts 1957). Architecture uses materials, textures, forms, and light to engage these senses. The assumption in this study is that light manipulation being an important element will push the spiritual experience towards a direction, whether positive or negative. The basis of spirituality relies on the connection between religion and feelings as religion is a source of profound emotions (The Psychology of Religion 2003; Emmons 2005). From a neuro-theological approach, the "emotional value operator" function of the mind mediates the experience of the sacred (Newberg and d'Aquili 2000).

This paper uses spiritual positive and negative emotions commonly provoked when people encounter sacred buildings. For instance, joy and content are associated with positive emotions, whereas fear and anxiety with the negative ones (Plutchik 1991). Awe appears prominently when talking about a relationship between humans and their gods (Keltner and Haidt 2003). Although hope as an emotion brings an assurance of eternal joy, as well as providing positive effects on the mental and physical health (Plutchik 1991; Emmons 2005). In Christianity, hope contemplates the eternal kingdom "Let us hold unswervingly to the hope we profess, for he who promised is faithful" (Hebrews 10:23). Such emotions are associated with spiritual experiences determined from psychology and psychology of religion scholarship. Thus, awe, hope, joy, content, peace, anxiety, fear, and sadness are used as emotional indicators of the spiritual experience in this study.

Although some scholars argue that spirituality being a subjective experience makes it harder or almost not relevant to measure empirically; others consider that quantitative measures should be developed to assess spirituality (Ramasubramanian 2014). Consequently, the objective is to empirically test the emotional responses to light manipulation in a virtual sacred space, more precisely, within a virtual church. The study constitutes a contribution to architectural design in the virtual realm as affecting human experiences. Such effects are measured by applying an empirical method prevalent in social sciences onto architectural research. The method consists of controlled experiments to assess the extent of the spiritual experience in a virtual context. The study's tool is composed of a video walkthrough of a virtual church followed by an online questionnaire. The questions are adapted from previously validated questionnaires used to measure religiosity, spirituality, and wellbeing in the psychology of religion and health research (e.g., Daily Spiritual Experience Scale (DSES), The Index of core spiritual experiences (INSPIRIT), etc.) (Kass et al. 1991; Newberg and d'Aquili 2000; Anandarajah and Hight 2001; Underwood and Teresi 2002; Unterrainer et al. 2010; Ahmad et al. 2015). Results of the study may be instrumental in enhancing and influencing the design approach to a virtual sacred space conditioned by its light design contributing to the spiritual experience of the worshiper. 


\section{Methodology}

The lack of empirical studies assessing the effect of light on the spiritual experience exhibits the need for an empirical examination that constitutes this paper's research question. This method will serve to augment and expand the already existing, yet limited, observational research and case studies. The main premise is to quantitatively test the effect of the manipulation of light intensity on the spiritual experience in a virtual church.

The strength of an experimental design lays in its power to generate causal inferences dealing with the effects of controlled independent variables and a measure of interest (Thorson et al. 2012). This method applies a quantitative approach that follows postpositivist perspectives by introducing the independent variables of the study as controlled treatments (light intensity) and creating an instrument in the form of a questionnaire to measure their impact on a variety of empirical manifestations of the dependent variables (emotions). The effects of the independent variables are subjected to appropriate statistical analysis (Creswell and Clark 2017).

In this study, digital religion is explored as the intersection of architecture, religion, and media. Specifically, an experimental methodology is used to test empirically if light, as a significant architectural element in sacred architecture, affects the spiritual experience of the worshiper in virtual church architecture (VCA) (Mansour and Geva 2018). The spiritual experience, communicated as the emotional responses of the participants, is measured on a heterogeneous sample of the Christian population in the United States of America, using a self-report online questionnaire following an exposure to variations of light intensity in a virtual church. Prior to the experiment, an approved proposal from the Institute Review Board (IRB) was obtained.

The study's method consists of four phases: (a) Setting up a digital/virtual context using a three dimensional model of a Christian building commonly found in games and similar virtual spaces. Then, creating various animated scenarios of the digital space; (b) developing an instrument (questionnaire) to measure the spiritual experience and use a web-based survey tool (Qualtrics) to collect data from the users' experiences. The questionnaire measures specific emotions, found in the literature, relating to spiritual experiences; (c) collecting data using a crowdsourcing internet marketplace, Amazon's Mechanical Turk (MTurk), where participants complete online Human Intelligence Tasks (HITs); and finally (d) managing, analyzing, and interpreting the data using statistical and graphical techniques (e.g., SPSS, R). The experimental design is represented as a linear flow chart in Figure 4.

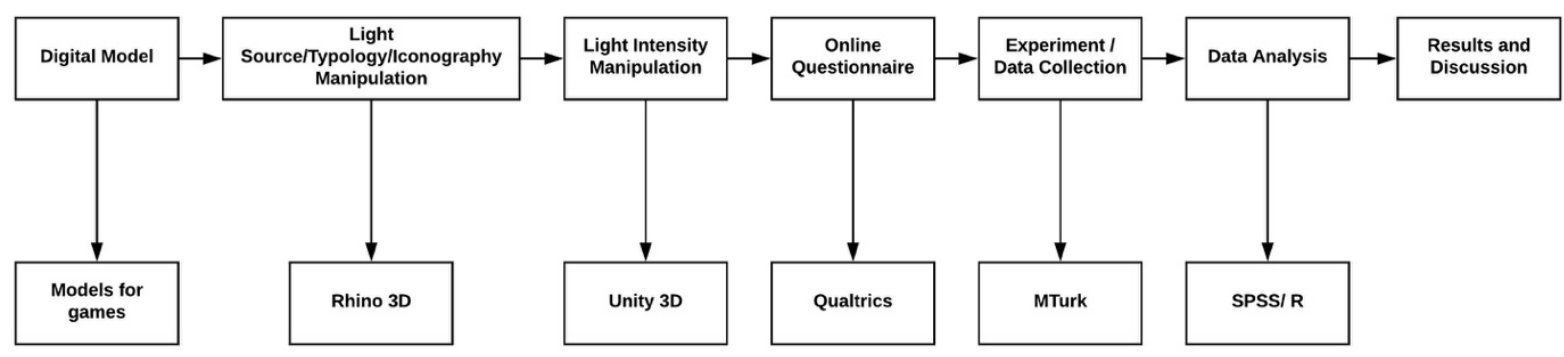

Figure 4. Study's experimental procedure flowchart.

The main hypothesis of this study states that the manipulation of light intensity (Bright and Dark) influences spiritual experience/emotions. The experiment's results will determine this effect quantitatively and serve as a precursor for lighting design guidelines that may enhance spiritual experiences by triggering specific emotions in virtual sacred spaces (church). Although the combination of sacred architectural elements such as light, shade, colors, materials, textures, plans, and icons creates the spirit that makes the space (Geva 2011), in this particular study, the focus is only on light as one of the most important elements of sacred architecture. For the case study, architectural light is expressed through the manipulation of its intensity. 


\subsection{Digital Context}

The literature review established Christian spaces as more commonly existing in the digital realm, especially in the United States (Gelfgren and Hutchings 2014). As a result, this study examines the spiritual experience in a virtual Christian church, whereas it establishes a platform that can also be applied to other religious buildings (i.e., mosques, synagogues, Hindu and Buddhist temples, etc.) To test the empirical methods' applicability, a case study of one church's architectural typology is used. Building Type 1 (BT1) displays an interior space characterized by the form of a cross plan, with a long nave divided by pillars, a transept, pointed arches and rib vaults evocative of a Romanesque style. Prominent height showing verticality and guiding the eyes towards the sky as a connotation of Heaven, large stained-glass windows along the sides topped with pointed arches, as well as three narrow and tall pointed windows enveloping the wall behind the apse. An intricate design rose window exists above the entrance. Figure 5 illustrates an awe-inspiring digital rendering of this church, expressing the image of a similar physical building used for worship.

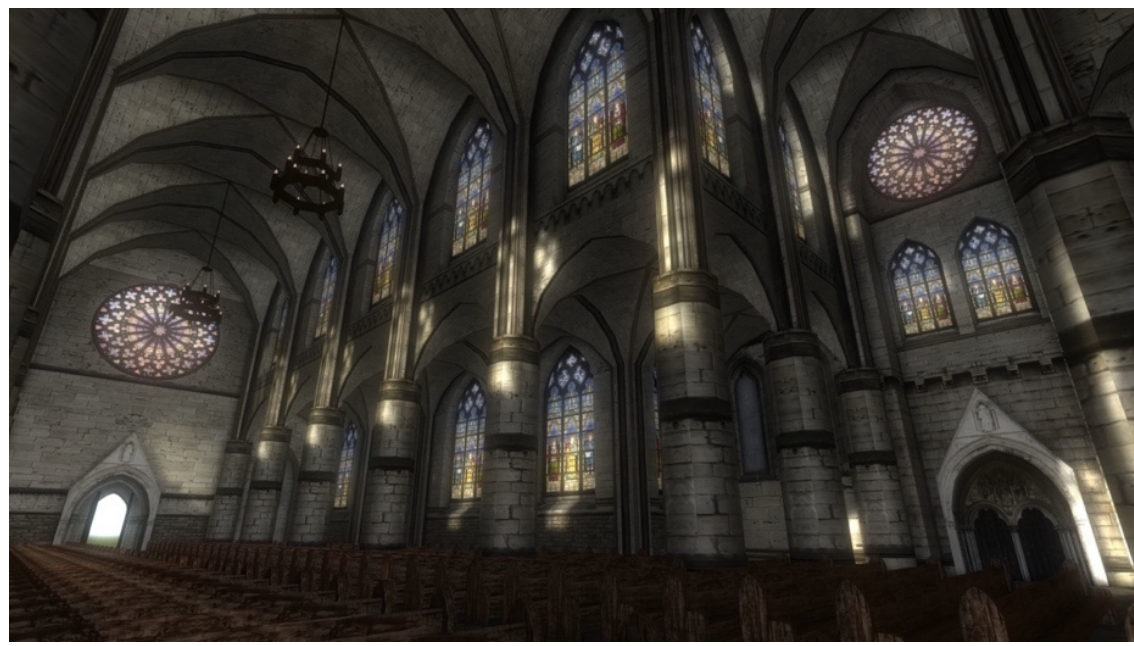

Figure 5. Building type 1 (BT1) church digital model: Back interior view.

Geometric transformations of the church are performed consisting of creating one major light source: large side windows (Figure 6). Christian icons are introduced in the space. The choice to include select and commonly recognizable icons serves to determine the difference in the effect of light with and without the presence of religious symbols (Figure 7). A game engine, Unity 3d, is used to render the light to create video animations of two scenarios of the church's walkthrough: bright light and dim/dark light. Unity's real time GI rendering method is used to simulate direct and indirect lighting. First, an ambient lighting is set up, then direct and indirect light intensities are modified (Figure 7).

After the light manipulation, the camera is set up at the eye level simulating a person walking through the space to create different video scenarios. The camera enters the church, stops for a second to look up, then looks down again and walks through the nave until reaching the altar. Once at the altar, the camera looks up one last time then returns back to eye level to look at the altar again. The same pace of the animation is set up for all the videos. The total length of the walkthrough is $45 \mathrm{~s}$. 


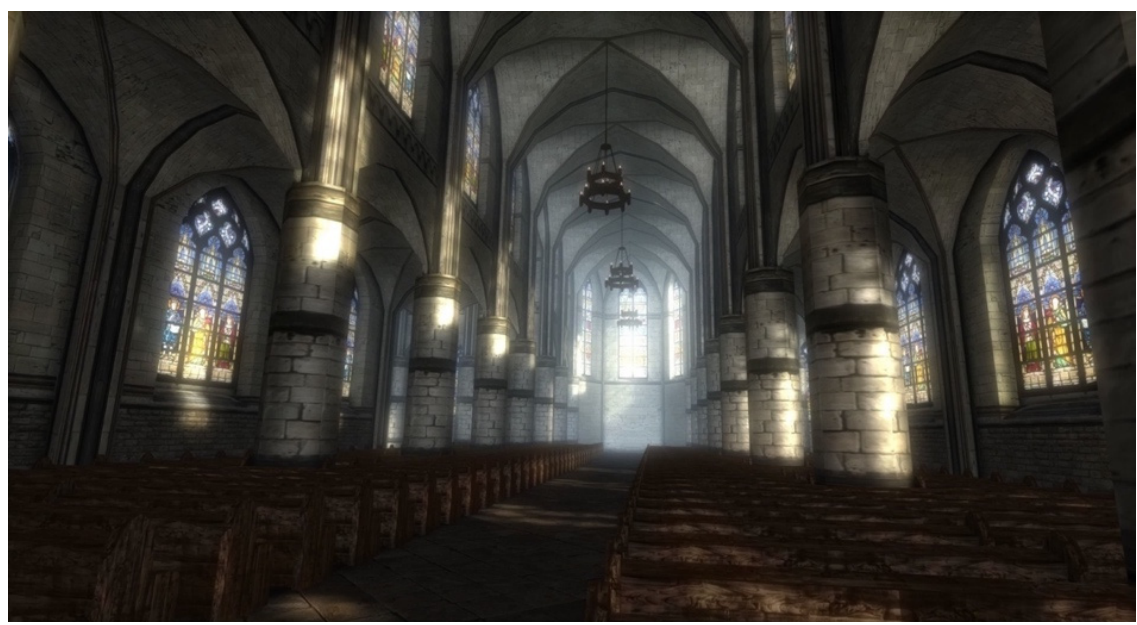

Figure 6. Building type 1 (BT1) church digital model: front interior view.

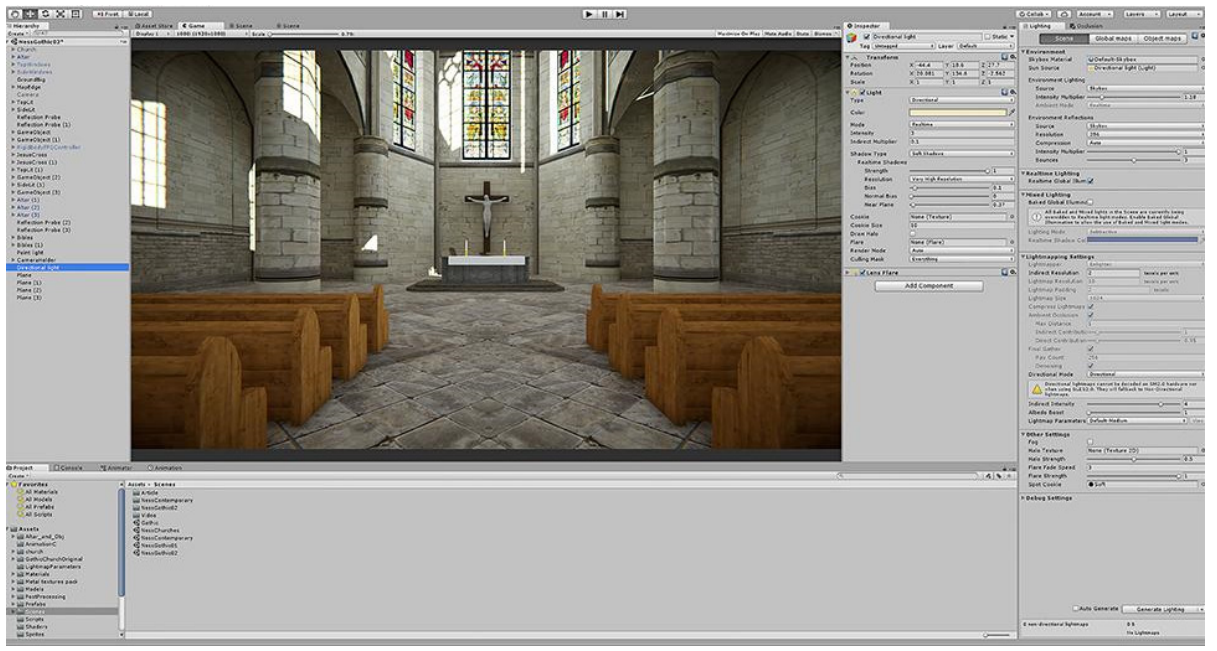

Figure 7. BT1 direct and indirect light manipulation: bright scene and iconography.

\subsection{Research Instrument}

The review of pertinent literature on the study of spirituality helped identify several questionnaires that relate to the evaluation of the spiritual experience and wellbeing. Researchers across disciplines rely on surveys to perform quantitative research (Dillman et al. 2014). Online surveys represent questionnaires that can be completed by the audience using digital technologies and the Internet (Dillman et al. 2014). The advantage is to aim a larger and broader audience that has access to the Internet while being economical since online surveys are designed as web forms available to large population, at low cost (Sue and Ritter 2011). The questionnaire used in this study was developed based on a combination of accepted and validated scales by researchers attesting that such instruments are valid in the assessment of spiritual experiences. A web-based survey tool, Qualtrics, is used to create the questionnaire that is later embedded in MTurk. Qualtrics has existed since 2002, and is considered a validated platform for researchers to conduct online surveys (Barnhoorn et al. 2015). Qualtrics enables the embedding and the equal randomization of the videos among all the participants. The use of an online survey method in the study of virtual architecture is an innovative way to assess the extent of spirituality as expressed by emotions in virtual environments. In fact, survey research allows us to measure a wide variety of unobservable data such as people's beliefs, emotions, and attitudes toward a stimulus, and remotely reach a large population that is hard to observe directly (Bhattacherjee 2012). 
The questions used address parameters such as the manipulation checks utilized to verify that the participants were sensitive to the amount of light in the virtual space. The assessments of the spirituality section of the questionnaire included items that directly addressed the extent of the spiritual feeling (emotions) the participants experienced on a Likert scale with anchors ranging from 0 to 10 , where 0 is Not at all and 10 is Very much. Six items addressed the experience of positive emotions ${ }^{3}$ and three items addressed the negative emotions ${ }^{4}$. Some examples of these questions are "To what extent were you able to experience AWE while watching the space in the video?" or "what emotions did you feel while watching the space in the video? please respond to each emotion stated in the list (hope, joy, comfort, peace, spiritual feeling, anxiety, fear, sadness)." The questionnaire also included several demographic items such as age, gender, level of education, etc.

\subsection{Data Collection}

For the past decade, researchers, especially in psychology undertaking behavioral research, have been using online labor markets such as Amazon Mechanical Turk (MTurk) where a large population sample can be tested at low cost (Barnhoorn et al. 2015). According to the World Bank Report in 2015, MTurk had a population of 500,000 people worldwide (Pew Research Center 2016). Despite concerns about the external validity of MTurk, studies showed the reliability of the data gathered using this platform (Chambers and Nimon 2017). The external validity was also demonstrated by comparing it with data gathered in a laboratory or using a university sample (Behrend et al. 2011). Therefore, the use of MTurk is an efficient way to have a more diverse and representative sample of the population (i.e., age, ethnicity, education, religious beliefs, etc.) rather than a students' sample, for example. In this study, a Human Intelligent Task (HIT) was created on MTurk. In the new HIT, a short description of the study and a selection criterion: Faith (needs to be Christian to participate), age, and location, were presented to the participants before they started the experiment. Participants had to comply with the conditions of the researcher in order to participate. They were randomly exposed to one of the two videos of the interior scenarios of the virtual church followed by the questionnaire. However, they had the choice to quit at any time they choose. Each participant could carry out the experiment only once, which avoids redundancy in participation that might affect the data collected.

\subsection{Data Analysis}

After all the questionnaires were completed, the collected data were downloaded from Qualtrics. Two steps were necessary at this level: data preparation and data analysis. Data preparation consists of data coding, where all the data are transformed into a numerical format. With coding, the data are then transferred to the Statistical Package software for Social Sciences (SPSS). Descriptive statistics are used for subjects' demographics data and association with religious practices and use of digital tools in religious practices. T-tests and ANOVAs (analysis of variance) were used to examine if the mean responses of the participants in the two conditions are statistically different from each other. This inferential analysis serves to test the main hypothesis that light intensity affects the spiritual experience in a virtual church.

\section{Case Study}

In this study, one experiment was performed, structured as a $2 \times 2$ in between group design (light intensity: Bright and Dark/Dim) representing only two conditions with the light source being the upper windows and the religious iconography being present in the space (Table 1). This experiment employs the manipulation of light intensity (Bright and Dark/Dim) in the virtual church as the Independent Variable (IV), and the spiritual experience that includes the emotions (spiritual feeling, positive, and negative emotions) as the dependent variable (DV) to measure. Intensity is one of the most important attributes of light. Also called luminance, it is considered by lighting designers and engineers to be the direct stimulus to vision and perception. Indeed, brightness is considered the most 
fundamental visual perception. Brightness is a function of the different reflectance of the surrounding objects under a uniform illumination and can range from very bright to dim or dark (DiLaura et al. 2011). According to the IES ${ }^{5}$ lighting handbook, studies conducted on spatial perceptions in built environments consider brightness and dimness to be the major factors in evaluating lighting conditions (DiLaura et al. 2011). Therefore, only the intensity of light is considered in this case.

Table 1. $2 \times 2$ Experimental design for the experiment: case study.

\begin{tabular}{cccc}
\hline & & Building Type I \\
\hline & & High Intensity of Light & Low Intensity of Light \\
\hline With Religious & Source of light & Group 1 & Group 2 \\
Iconography & Upper Windows & $\mathrm{N}=25$ & $\mathrm{~N}=25$ \\
\hline
\end{tabular}

The participants consist of MTurk workers randomly watching one of the two available videos of the "walkthrough" in the virtual church's nave. Only two scenarios of the "walkthrough" were introduced: high and low light intensities (as described in detail in the methodology section).

While walking along the nave of the church in a steady manner, architectural elements present in the space could be noticed: columns, arches, windows with stained glass, pews, high ceiling, altar, crucifix, candles, etc. The walkthrough video lasts $45 \mathrm{~s}^{6}$ starting from the entrance to the altar through the nave. The sample size used in this experiment is $\mathrm{N}=50$, (25 participants watched the video with the bright light condition, and 25 with the dark/dim light condition). The randomization of the videos allows an equal exposure and minimizes the individual differences that may extraneously affect the results.

\section{Results and Analysis}

The results of this investigation unfold into three levels. First, the statistical analysis demonstrated that participants accurately perceived the light intensity manipulation performed (bright and dark/dim), which yields internal validity to the experiment. Internal validity attests if an observation determines a causal relationship between the independent and dependent variables (Calder et al. 1982). Second, spirituality in this study is measured through a series of nine questions inquiring about distinct emotional responses such as awe, hope, joy, peace, comfort, spiritual feeling, sadness, fear, and anxiety. The structure of the responses suggested that the spiritual experience is manifested into two distinct clusters, i.e., positive emotions and negative emotions. Third, light intensity, which represents the key manipulation of the independent variable, has an effect on the spiritual experience. This result confirms the hypothesis of this study which is: light intensity impacts the spiritual experience in a virtual church.

\subsection{Light Intensity Manipulation Check}

This manipulation check serves as a validation that the participants were able to notice the change in light intensity while watching the video of the church walkthrough. To test this effect, a comparison of means is used with a $t$-test of Independent Samples where the test-dependent variable is Light (as perceived by the participants), and the independent grouping variable is light intensity that is manipulated in the videos-and varies between bright and dark. This method serves to check if the light intensity manipulation is perceived across the entire sample. The response to the question, "how much light did you see in the video?" on a scale from 0 to 10 serves to test the light manipulation. The results show that the manipulation of light intensity in the videos was indeed strongly perceived by the subjects $\left[\mathrm{t}_{(48)}=5.12, p<0.028\right]$. These results confirm the significance of manipulation of light intensity across both video conditions and across the population sample of 50 . Moreover, Figure 8 shows the comparison of means affirming light was indeed noticed by the participants more in the bright scenario with $\mathrm{M}=7.04$ than in the dark/dim one with a 
mean $M=5.59$. These results enable us to conclude that light intensity manipulation was highly perceived by the participants in the whole sample and across both conditions.

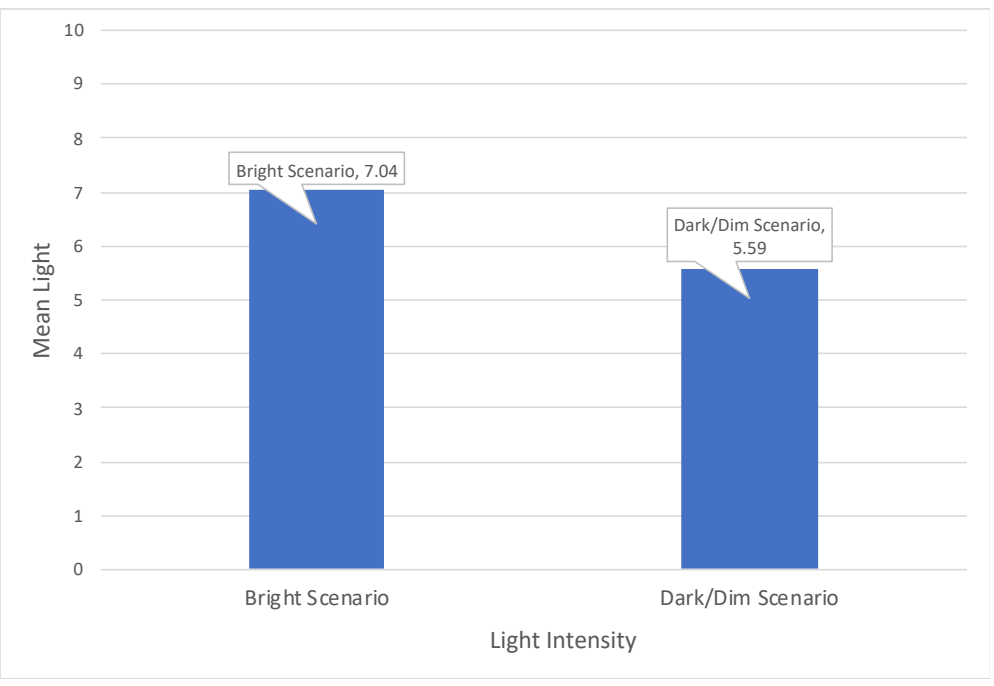

Figure 8. Light intensity manipulation check: comparison of means.

\subsection{Measurement of Spirituality}

Spirituality in this study was measured in two ways. First, through a direct item that asks participants to report the spiritual feeling they experienced after watching the video of the church (on a scale for 0 to 10). The second was a series of eight items consisting of distinct emotional responses such as awe, hope, joy, peace, comfort, sadness, fear, and anxiety. To explore the conceptual structure of the emotional items and relate them to this work, a factor analysis of these items based on the entire sample was performed. This factor analysis determines the inter-relationship or the consistency among the items related to emotions. The principal component analysis generated two identifiable clusters both showing an acceptable distinction between positive and negative emotions as stated in the psychology of religion literature. The first cluster represents the positive emotions: awe, hope, joy, comfort, and peace. The second cluster represents the negative emotions of anxiety, fear, and sadness. Consequently, an index score is created for each of the two emotion clusters (averaging the appropriate scales). This index score was used later on to analyze the effect of light intensity on each emotional cluster.

In addition to the positive and negative emotion clusters, another scale was used as a direct question inquiring about the spiritual feeling of the participants. The results show a positive correlation between the spiritual feeling and the positive emotions, though the direct spirituality scale is not correlated with the negative emotions. These results can deduct that the spiritual feeling is mainly linked to the positive emotions that are higher than the negative ones.

\subsection{Effect of Light Intensity on the Spiritual Experience: Positive and Negative Emotions}

To address the hypothesis of this study that light intensity has an effect on the spiritual experience as an emotional reaction, a combination of T-tests and ANOVA (analysis of variance) were performed on positive and negative emotions. The ANOVA results show a significant effect of light intensity on the spiritual experience [F $(1,46)=12.58 p<0.001]$. Additionally, overall, more positive emotions were felt $(\mathrm{M}=4.05)$ than negative ones $(M=1.93)$, regardless of the lighting scenarios (bright or dark/dim). These results support the hypothesis that light has an effect on spiritual experience as it impacts the emotions in this study.

However, the results in this particular case study show that light intensity had more effect on the negative emotions in the bright scenario $[(t(1,48)=3.97 p<0.05)]$. The lighter the space, the more negative emotions (sadness, fear, anxiety) were felt by the participants 
$(\mathrm{M}=2.65)$ than positive ones $(\mathrm{M}=1.21)$. Participants experienced similar positive emotions in both the bright and dark/dim church scenarios (Figure 9).

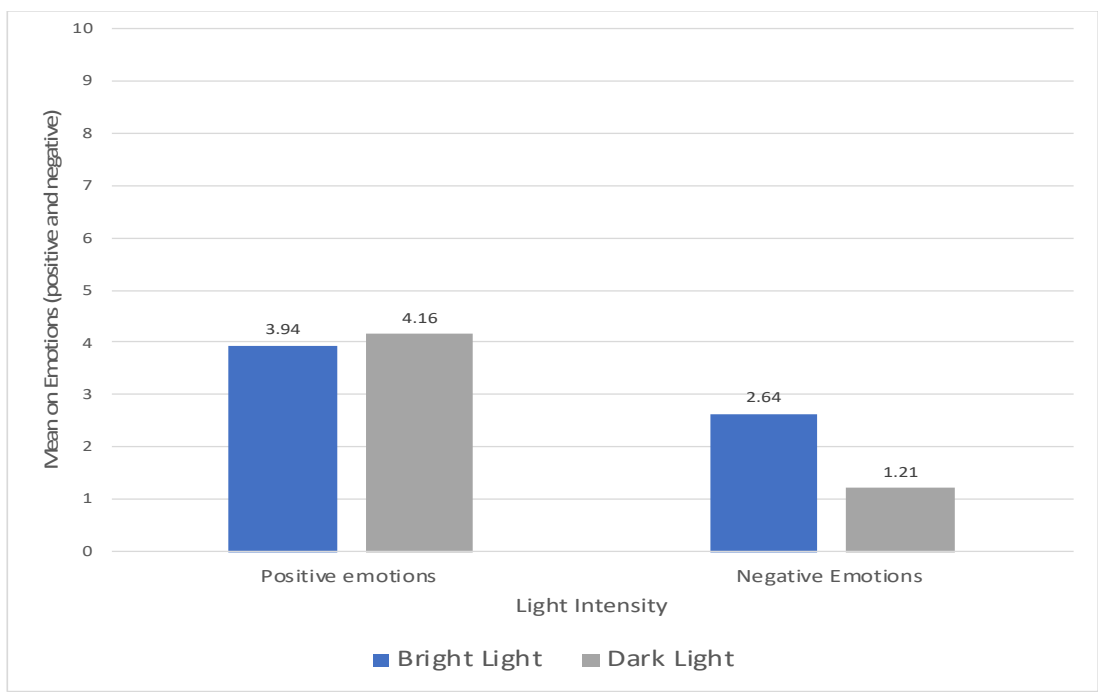

Figure 9. Effect of light intensity on positive and negative emotions.

In conclusion, this preliminary test of the experiment was used to show the efficiency of the methodology and the platforms used (Unity 3D, Qualtrics, Mturk). In addition, despite the small sample $(\mathrm{N}=50)$ the light manipulation was significant, which confirms the overall hypothesis of this research, stating that light has an effect on the spiritual experience in virtual sacred architecture.

However, a supplemental experiment on a bigger sample ought to yield more significant results of the effect of light on positive and negative emotions, in addition to accomplishing the external validity of the experiment.

\section{Discussion and Conclusions}

The importance of this paper relies mostly on the designed experiment to assess the effect of light on the spiritual experience of worshipers in virtual sacred architecture. The article attempts to fill two gaps: the first relates to digital religion scholarship that focuses on the textual narrative of religion and pays less or no deep attention to the visual representation of sacred spaces in the digital realm; the second relates to the lack of empirical studies of light effects on spirituality in sacred architecture and none in virtual sacred environments. This experience can be considered a spiritual appreciation of architectural elements translated as subjective emotional responses to virtual sacred architecture.

The main hypothesis of this study stating that the manipulation of light intensity (bright and dark/dim) in the virtual church has an effect on the spiritual experience/emotions was supported by the findings of the experiment. Indeed, the results show that light has an effect on the emotions (positive and negative). The results comply with the two IES guidelines for the lighting design in houses of worship that are required to have spiritual light as an architectural or ambient light to reveal architectural features, and accent light that enhances religious symbols (Clarahan 2004; DiLaura et al. 2011). Therefore, the experiment established that light intensity is indeed an important factor to consider when designing sacred architecture. However, although in this specific case study the bright scenario elicited more negative emotions than the positive ones, the results do not provide enough evidence to conclude that more light in the space triggers more negative emotions. Further studies should be performed in the future using a bigger sample size to determine the validity of such a statement.

In conclusion, the results supported the claim that light intensity has an effect on the spiritual experience/emotions in a virtual church, which reinforces the concept of holy light 
in Christianity. The results draw attention to major outcomes. First, the advantages of applying social sciences research design and methodology to investigate digital architectural contexts. This research approach provides an opportunity and a requirement to rephrase our architectural theories with more precision that makes them testable rather than only observational. Second, this inquiry enables the representation of sacred architectural spaces using digital media and increasing the potential of exploring design variations in virtual spaces and lighting. This is particularly applicable today, as the world is experiencing a global pandemic where face-to-face activities have become limited.

Additionally, such empirical investigations provide an innovative way to assess emotional reactions to sacred architectural spaces and can be used, such as in this paper, in digital spaces that could extend to real ones. They also raise the awareness of the digital religion phenomenon and its virtual space design. Further, this provides an assessment tool for digital architectural design in virtual religious spaces that so far was left to web and game designers or digital artists rather than more experienced architects and designers, in terms of the sacred. Light remains the variable that affects not only the emotional response expressing the spiritual experience, but also the perception of the space. The originality and uniqueness of this research is expressed along two dimensions: (a) for the first time, the assessment of spiritual experience is conducted in virtual sacred architecture; (b) it meets the challenge of quantitative evaluation of spirituality, whereas spirituality is often treated as a subjective experience that is considered difficult to measure empirically.

The study of light as well as the adaption of such empirical method may become a basis for a tool used to analyze spirituality in virtual sacred architecture, not just in Christianity but also in other faiths/religions and their houses of worship (e.g., Islam, Judaism, Buddhism, etc.). It can provide additional input on lighting design criteria able to enhance spiritual experiences in real and virtual sacred spaces. For instance, design guidelines for the use of light intensity (high, or low) highlighting architectural elements and symbols presumed to be important in eliciting emotional experiences. Although the focus was on light intensity, future experiments should incorporate more variables to test: light color, materials, textures, and acoustics (sound/silence). This is particularly applicable as we move towards the metaverse, which represents a virtual reality version of the Internet based on three-dimensional graphic representations. At the end, this empirical study fosters attention to the virtual light which becomes the 'holy light' of cyberspace.

Funding: This research received no external funding.

Institutional Review Board Statement: The study was conducted in accordance with the Declaration of Helsinki, and approved by the Institutional Review Board (or Ethics Committee) of Texas A\&M University (IRB2016-0274D, 08/09/2017).

Informed Consent Statement: Informed consent was obtained from all subjects involved in the study.

Conflicts of Interest: The author declares no conflict of interest.

\section{Notes}

1 E-Church can also be called online church, cyber church, internet church, is a space that uses the internet to enable religious activities such as prayers, rituals, discussion forums that all happen online. They are intrenet-based religious communities that started in the $2000^{\prime} \mathrm{s}$. This space could be a wesbite, bible study application, chatroom or discussion board, podcast, TV broadcasting, etc.

2 The specific use of the term "digital religion" instead of "digital theology" or "cyber religion" stems from the fact that it explores numerous and diverse facets of religious dimensions that can be found in the web. In addition, digital religion was the first term used to identify the new phenomenon of the study of religion and digital media.

Awe, hope, joy, comfort, peace.

Anxiety, fear, sadness.

Illuminating Engineering Society (IES).

The length of the video is based on a previous experiment to record the perception of light in the virtual space. 


\section{References}

Abu-Taieh, Evon, Issam H. Al Hadid, and Abdelkrim El Mouatasim. 2020. Cyberspace. Norderstedt: Books on Demand.

Ahmad, Nahdatul Akma, Azaliza Zainal, Fariza Hanis Abdul Razak, Wan Adilah Wan Adnan, and Salyani Osman. 2015. User Experience Evaluation of Mobile Spiritual Applications for Older People: An Interview and Observation Study. Journal of Theoretical \& Applied Information Technology 72: 76-85.

Anandarajah, Gowri, and Ellen Hight. 2001. Spirituality and Medical Practice: Using the HOPE Questions as a Practical Tool for Spiritual Assessment. American Family Physician 63: 81. [PubMed]

Barnhoorn, Jonathan S., Erwin Haasnoot, Bruno R. Bocanegra, and Henk van Steenbergen. 2015. QRTEngine: An Easy Solution for Running Online Reaction Time Experiments Using Qualtrics. Behavior Research Methods 47: 918-29. [CrossRef] [PubMed]

Behrend, Tara S., David J. Sharek, Adam W. Meade, and Eric N. Wiebe. 2011. The Viability of Crowdsourcing for Survey Research. Behavior Research Methods 43: 800. [CrossRef] [PubMed]

Bento, Regina. 2000. The Little Inn at the Crossroads: A Spiritual Approach to the Design of a Leadership Course. Journal of Management Education 24: 650-61. [CrossRef]

Bermudez, Julio. 1999. Between Reality and Virtuality: Towards a New Consciousness. Reframing Consciousness. Available online: https:/ / www.academia.edu/4026158/Between_Reality_and_Virtuality_Toward_a_New_Consciousness (accessed on 11 November 2017).

Bhattacherjee, Anol. 2012. Social Science Research: Principles, Methods, and Practices. Available online: https://digitalcommons.usf. edu/cgi/viewcontent.cgi?article=1002\&context=oa_textbooks (accessed on 6 August 2018).

Birch, Robert, and Brian R. Sinclair. 2013. Spirituality in Place: Building Connections Between Architecture, Design, and Spiritual Experience. In ARCC Conference Repository. New York: Routledge.

Calder, Bobby J., Lynn W. Phillips, and Alice M. Tybout. 1982. The Concept of External Validity. Journal of Consumer Research 9: 240-44. [CrossRef]

Campbell, Dace. 1995. Design in Virtual Environments Using Architectural Metaphor. Available online: http:/ / papers.cumincad.org/ data/works/att/b27f.content.pdf (accessed on 6 September 2018).

Campbell, Heidi. 2005. Exploring Religious Community Online: We Are One in the Network. New York: Peter Lang.

Campbell, Heidi. 2012. Digital Religion: Understanding Religious Practice in New Media Worlds. London: Routledge.

Campbell, Heidi, and Ruth Tsuria. 2021. Digital Religion: Understanding Religious Practice in Digital Media. London and Boca Raton: Routledge \& CRC Press.

Carroll, Thomas K. 2003. Architecture and Spirituality. Irish Theological Quarterly 68: 35-50. [CrossRef]

Chambers, Silvana, and Kim Nimon. 2017. Conducting Survey Research Using MTurk. In Handbook of Research on Innovative Techniques, Trends, and Analysis for Optimized Research Methods. Hershey: IGI Global, p. 258.

Clarahan, Mollie M. 2004. Inspired Illumination. Your Church 50: 42-44.

Corbusier, Le. 1931. Towards a New Architecture. Washington, DC: Courier Corporation.

Creswell, John W., and Vicki L. Plano Clark. 2017. Designing and Conducting Mixed Methods Research. Thousand Oaks: Sage Publications.

DiLaura, David L., Kevin W. Houser, Richard G. Mistrick, and Gary R. Steffy. 2011. The Lighting Handbook: Reference and Application. New York: Illuminating Engineering Society of North America New York.

Dillman, Don A., Jolene D. Smyth, and Leah Melani Christian. 2014. Internet, Phone, Mail, and Mixed-Mode Surveys: The Tailored Design Method. New York: John Wiley \& Sons.

Emmons, Robert A. 2005. Emotion and Religion. In Handbook of the Psychology of Religion and Spirituality. New York: Guilford Publications, pp. 235-52.

Gelfgren, Stefan, and Tim Hutchings. 2014. The Virtual Construction of the Sacred-Representation and Fantasy in the Architecture of Second Life Churches. Nordic Journal of Religion and Society 27: 59-73. [CrossRef]

Geva, Anat. 2011. Frank Lloyd Wright's Sacred Architecture: Faith, Form and Building Technology. London: Routledge.

Gibson, William. 1984. Neuromancer. Harmondsworth: Penguin.

Gojnik, Zorana Sokol, and Igor Gojnik. 2018. Constitutive Role of Light in Christian Sacred Architecture. Paper presented at the ICRAC 2018: 20th International Conference on Religious Architecture and Cultures, Cape Town, South Africa, November 4-5.

Helland, Christopher. 2016. Digital Religion. In Handbook of Religion and Society. Edited by David Yamane. Cham: Springer International Publishing, pp. 177-96.

Hoover, Stewart, and Nabil Echchaibi. 2012. The 'Third Spaces' of Digital Religion. Finding Religion in the Media 5. [CrossRef]

Hutchings, Tim. 2011. Contemporary Religious Community and the Online Church. Information, Communication E Society 14: 1118-35.

Jamiecat. 2010. The Church. Photo. Available online: https://www.flickr.com/photos/jamiecat/4447023973/ (accessed on 7 February 2019).

Jones, Lindsay. 2000. The Hermeneutics of Sacred Architecture: Hermeneutical Calisthenics: A Morphology of Ritual-Architectural Priorities. Cambridge: Center for the Study of World Religions, Harvard University, vol. 2.

Kalay, Yehuda E. 2004. Architecture's New Media: Principles, Theories, and Methods of Computer-Aided Design. Cambridge: MIT Press.

Kalay, Yehuda, and John Marx. 2005. Architecture and the Internet: Designing Places in Cyberspace. First Monday, October 11.

Kass, Jared D., Richard Friedman, Jane Leserman, Patricia C. Zuttermeister, and Herbert Benson. 1991. Health Outcomes and a New Index of Spiritual Experience. Journal for the Scientific Study of Religion 30: 203-11. [CrossRef] 
Keltner, Dacher, and Jonathan Haidt. 2003. Approaching Awe, a Moral, Spiritual, and Aesthetic Emotion. Cognition and Emotion 17: 297-314. [CrossRef] [PubMed]

Lewis, Jeffrey S., and Gary D. Geroy. 2000. Employee Spirituality in the Workplace: A Cross-Cultural View for the Management of Spiritual Employees. Journal of Management Education 24: 682-94. [CrossRef]

MacDonald, Lindsay. 2006. Digital Heritage. London: Routledge.

Mansour, Nesrine, and Anat Geva. 2018. Displacement in the Era of Digital Religion and Virtual Sacred Architecture. Available online: https://www.academia.edu/37983986/Displacement_In_The_Era_Of_Digital_Religion_And_Virtual_Sacred_Architecture (accessed on 15 September 2019).

Matracchi, Pietro, and Ali Sadeghi Habibabad. 2021. Explaining and Evaluating the Quality of 'Light' in Religious Environments and Its Effect on Spirituality-ScienceDirect. Frontiers of Architectural Research 10: 803-20. [CrossRef]

Newberg, Andrew B., and Eugene G. d'Aquili. 2000. The Neuropsychology of Religious and Spiritual Experience. Journal of Consciousness Studies 7: 251-66.

Ning, Huansheng, Xiaozhen Ye, Mohammed Amine Bouras, Dawei Wei, and Mahmoud Daneshmand. 2018. General Cyberspace: Cyberspace and Cyber-Enabled Spaces. IEEE Internet of Things Journal 5: 1843-56. [CrossRef]

Palmer, Parker J. 2003. Teaching with Heart and Soul Reflections on Spirituality in Teacher Education. Journal of Teacher Education 54: 376-85. [CrossRef]

Parry, Ross. 2007. Recoding the Museum: Digital Heritage and the Technologies of Change. London: Routledge.

Pew Research Center. 2016. The Size of the Mechanical Turk Marketplace I Pew Research Center Report. Available online: https: //www.pewinternet.org/2016/07/11/the-size-of-the-mechanical-turk-marketplace/ (accessed on 28 May 2019).

Plummer, Henry. 1987. Poetics of Light. Santa Fe: Museum of New Mexico Press.

Plutchik, Robert. 1991. The Emotions. New York: University Press of America.

Rafeejewell. 2009. ART AT BASILICA CARDINALE. Photo. Available online: https://www.flickr.com/photos/raftwetjewell/31748920 33/ (accessed on 7 July 2019).

Rain, Ottis, and Peeter Lorents. 2010. Cyberspace: Definition and Implications-ProQuest. Available online: https://www.proquest. com/docview /869617247?pq-origsite=gscholar / (accessed on 16 January 2020).

Ramasubramanian, Srividya. 2014. Media and Spirituality. In Media and Social Life. Edited by Mary Beth Oliver and Arthur Raney. New York: Routledge, pp. 46-62. [CrossRef]

Saint Jean Cathedral in WebGL. 2019. Available online: http://patapom.com/topics/WebGL/cathedral/index.html (accessed on 9 February 2019).

Schroeder, Ralph, Noel Heather, and Raymond M. Lee. 1998. The Sacred and the Virtual: Religion in Multi-User Virtual Reality. Journal of Computer-Mediated Communication 4: 1-2. [CrossRef]

Schwarz, Rudolf. 1958. The Church Incarnate: The Sacred Function of Christian Architecture. Newport Coast: Franklin Classics.

Sue, Valerie M., and Lois A. Ritter. 2011. Conducting Online Surveys. Thousand Oaks: SAGE Publications.

The Psychology of Religion. 2003. Annual Review of Psychology 54: 377-402. [CrossRef]

The Sanctuary App on the App Store. 2011. Available online: https://itunes.apple.com/us/app/the-sanctuary-app/id568865203?mt=8 (accessed on 9 February 2019).

Thorson, Esther, Rob Wicks, and Glenn Leshner. 2012. Experimental Methodology in Journalism and Mass Communication Research. Journalism \& Mass Communication Quarterly 89: 112-24.

Thwaites, Harold. 2013. Digital Heritage: What Happens When We Digitize Everything? In Visual Heritage in the Digital Age. Edited by Eugene Ch'ng, Vincent Gaffney and Henry Chapman. Springer Series on Cultural Computing; London: Springer London, pp. $327-48$.

Underwood, Lynn G., and Jeanne A. Teresi. 2002. The Daily Spiritual Experience Scale: Development, Theoretical Description, Reliability, Exploratory Factor Analysis, and Preliminary Construct Validity Using Health-Related Data. Annals of Behavioral Medicine 24: 22-33. [CrossRef] [PubMed]

Unterrainer, Human Friedrich, Karl Heinz Ladenhauf, M. L. Moazedi, Sandra Johanna Wallner-Liebmann, and Andreas Fink. 2010. Dimensions of Religious/Spiritual Well-Being and Their Relation to Personality and Psychological Well-Being. Personality and Individual Differences 49: 192-97. [CrossRef]

Wagner, Rachel. 2013. Understanding Religious Practice in New Media Worlds. New York: Digital Religion.

Watts, Alan. 1957. The Way of Zen. New York: Pantheon.

Woywod, Stanislaus. 1918. The New Canon Law: A Commentary and Summary of the New Code of Canon Law. New York: JF Wagner.

Zinnbauer, Brian J., Kenneth I. Pargament, and Allie B. Scott. 1999. The Emerging Meanings of Religiousness and Spirituality: Problems and Prospects. Journal of Personality 67: 889-919. [CrossRef] 